Original Research Paper

\title{
An Entire-Array-Polygon (EAP) Method to Assess Urban Development Suitability
}

\author{
Long Cheng and Yan Liu \\ School of Geography, Planning and Environmental Management, \\ The University of Queensland, Brisbane 4067, Australia
}

Article history

Received: 11-01-2016

Revised: 20-04-2016

Accepted: 01-07-2016

Corresponding Author:

Long Cheng

School of Geography, Planning and Environmental

Management, The University of Queensland, Brisbane 4067,

Australia

Email: 1.cheng1@uq.edu.au

\begin{abstract}
China has been experiencing rapid urbanization since the economic reforms and open-up in the late 1970s, with the expansion and restructuring of existing cities taking place at an unprecedented pace, as well as the emergence of many new cities. However, it remains a challenge for urban planners and decision-makers to identify and assess the suitability of areas for future urban development. Building on previous studies, this paper presents a novel approach using an Entire-Array-Polygon (EAP) method to assess the urban development suitability in the fast developing city-region in China. A suitability indicator system was developed to reflect the environmental and economic conditions as well as the living conditions of residents. A major advantage of the EAP model is that it does not rely on the assignment of weight ages for different indicators. Instead, all factors are mapped against one standardised platform. An application of the EAP model in Ezhou, a medium-scale city adjacent to the provincial capital city of Wuhan in Hubei Province, China, over a 15 -year period (1998-2012) shows a differentiated suitability evolution for urban development in its three districts, Echeng, Huarong and Liangzihu. While Echeng remains most suitable for urban development, its development suitability decreased sharply from 1998 to 2009, indicating limited space for further growth. In contrast, the suitability in Huarong increased significantly attributed to rapid development of Gedian Economic and Technological Development Zone, while Liangzihu district experienced marginal increase in urban development suitability due to limited land space as well as the conservation of the Liangzi Lake. Our application demonstrates that the EAP method is effective in assisting planners to assess urban development suitability and identify potentials for future development.
\end{abstract}

Keywords: Entire-Array-Polygon (EAP) Method, Urbanization, Development Suitability, Ezhou

\section{Introduction}

In 2008, for the first time in history, more than half of the world's population lived in urban areas (UNPF, 2007). Due to the greater opportunities that cities offer, the urban population is projected to double in the next twenty years, which will unavoidably result in further expansions of urban areas (Glaeser, 2011; Nolè et al., 2014). In China, the rate of urbanization has been accelerating since its economic reforms and open-up in the late $1970 \mathrm{~s}$ (Deng et al., 2008); the urban population in China has been increasing by 1315 million per year since 1978. The number of prefecture-level cities increased from 98 in 1978 to 286 in 2013 (NBSC, 1978; 2014) and urban built-up areas have been expanding continuously at over six percent per annum since the mid-1980 s (Lu, 2011). This rapid urbanization has imposed significant pressures on the environment and the limited natural resources (Jago-on et al., 2009) and therefore, achieving sustainable development goals in China and globally by identifying and assessing land that is most 
suitable for urban development becomes more challenging for urban planners and decision-makers (Collins et al., 2001; Hopkins, 1977).

Land suitability assessment is a typical exercise in geography, with the aim to identify the most suitable site for a certain purpose. It has been applied in a variety of areas, ranging from defining suitable land or habitant for animal and plant species (Pereira and Duckstein, 1993; Store and Kangas, 2001), assessing land suitability for agriculture (Akinci et al., 2013; Feizizadeh and Blaschke, 2012), to landscape evaluation and planning (Girvetz et al., 2008; Kienast et al., 2012) and regional planning and environmental impact assessment (Marull et al., 2007; Steiner et al., 2000). With regard to urban development, various approaches have been developed to evaluate a suite of land suitability attributes, where the most common approaches are the GIS based Multi-Criteria Analysis (MCA) and the expert-led Analytic Hierarchy Process (AHP) approach (Chandio et al., 2011; Dong et al., 2008; Jain and Subbaiah, 2007; Kumar and Shaikh, 2012; Liu et al., 2014; Malczewski, 2006; Youssef et al., 2010). More recently, new methods such as spatially-explicit sensitivity analysis (Xu and Zhang, 2013) and BackPropagation (BP) Neural Network method (Xu et al., 2011) have been applied to validate and calibrate the Multi-Criteria Decision-Making (MCDM) techniques in order to evaluate land suitability for urban development.

While GIS based multi-criteria analysis is powerful in incorporating the spatially referenced data into a decisionmaking process (Mendas and Delali, 2012), a major limitation of this approach in land suitability analysis is the underrepresentation of non-geographical factors. The most commonly applied criteria in the multi-criteria method include land slope, proximity to roads and other infrastructure facilities, land use and land cover, geological formation and so on. This approach typically does not take into account non-physical factors such as the socio-economic and institutional factors which also play important roles in affecting land use suitability, especially for urban development; an area with a promising socioeconomic outlook could gain favour financially and politically for urban development. Consequently, such developments can also boost local economic growth and improve human living conditions, an important prerequisite for urban development. Hence, such nonphysical factors also need to be taken into consideration when assessing the urban development suitability.

There is also a challenge in assigning weight age for different attributes in the multi-criteria analysis. The commonly used approach is the AHP approach, a qualitative multi-criteria decision making method based on pair wise comparisons (Saaty, 1980). The AHP approach attempts to solve complex and unstructured problems by breaking them down into a set of component factors and offers some advantages over the classical suitability analysis. It relies less on the completeness of the data but more on expert opinions or observations of perceived suitability effects which are largely subjective, especially when assessing the socioeconomic factors for urban development (Liu et al., 2013). There is an urgent need for more robust methods to facilitate the assessment of land suitability for potential urban development.

This paper presents a novel approach using an EntireArray-Polygon (EAP) method to evaluate land suitability for urban development. This approach was initially proposed by Wu et al. (2005) to evaluate the suitability of an eco-city construction in Yangzhou City, China. Through a process of data standardization, all identified indictors were mapped to one standardized platform as a radar chart for each spatial unit under assessment, where the ratio of the radar polygon to the entire radar area is calculated to represent the overall suitability of the land unit for development. This method is easier to visually compare different indicators of multiple units under assessment in order to assess their advantages and disadvantages. Given that this approach does not require the subjective assignment of weight ages to the indicators, the EAP approach has been applied to evaluate regional ecological and economic development suitability (Wang and Bian, 2007), mega-city evolution (Liu et al., 2013) and intensive land use potentials (Cheng and Dong, 2013). However, the original EAP approach proposed by $\mathrm{Wu}$ et al. (2005) used a data standardization method based on time series data for the whole city and the suitability computed depends on the time period duration. It means the suitability result could vary along with different time period and relies on a strict requirement for continuity and richness in the data. Given that, this paper proposes a revised EAP approach to assess urban development suitability, using in a rapidly developing region in central China as a case study to understand the spatial and temporal evolution of urban development suitability. By incorporating an improved standardization and synthesis method, our approach also contribute to improve the original EAP method by assessing a suite of suitability indicators to reflect the three dimensions of development suitability, including environmental conditions, economic and human living conditions.

The rest of this paper is structured as follows. The following section presents the study area and the data used. Section 3 introduces the methodology, including the construction of a suitability indicator system, data standardization method and EAP model. Section 4 applies the EAP model to assess the urban development suitability in Ezhou City over two time points (1998 and 2012). The results are and discussed in this section with the conclusions presented in the last section. 


\section{The Study Area and Data}

Ezhou City is a fast growing medium sized city located in the middle reaches of the Yangtze River, adjacent to the provincial capital of Wuhan City in Hubei Province in central China (Fig. 1). Geographically, it is located at longitude from $114^{\circ} 30^{\prime} \mathrm{E}$ to $115^{\circ} 05^{\prime} \mathrm{E}$ and at latitude from $30^{\circ} 01^{\prime} \mathrm{N}$ to $30^{\circ} 36^{\prime} \mathrm{N}$, with an area of $1500 \mathrm{~km}^{2}$ and a population of 1.09 million in 2013 (HSB, 2014). There are three district-level units, namely Echeng, Huarong and Liangzihu. As a core part of the Wuhan Metropolitan Agglomeration (WMA) in central China, Ezhou has benefited from its close proximity to the capital city for both economic and social development. In 2013, its Gross Domestic Product (GDP) reached 63.1 billion Yuan (USD\$ 9.95 billion), an increase of $10.5 \%$ from the previous year (HSB, 2014).

The urban system in Ezhou comprises of a four-level structure, including one city centre, three county-scale districts, a number of towns and local communities. In 2008, Ezhou was selected as part of a few pilot test cities to implement a new urban development policy, the Integrated Urban and Rural Development Programme in China, aiming to promote sustainable and balanced development for urban and rural areas. By 2013, the urban population in Ezhou had reached 0.664 million, or $62.8 \%$ of its total population (HSB, 2014), an urbanization rate that is only second to the provincial capital of Wuhan city in Hubei Province.

To testify the applicability of the EAP model for urban development suitability evaluation, the three county-level districts-Echeng, Huarong and Liangzihu-were selected as the basic geographical unit for analysis, as this is the lowest administrative unit where socio-economic data is available. Two time points in 1998 and 2012 were used to assess how urban development suitability has evolved over the 15 year period. The year 1998 was selected as a base line prior to the implementation of the integrated urbanrural development programme and the year 2012 represents the most recent year where socio-economic data is available.

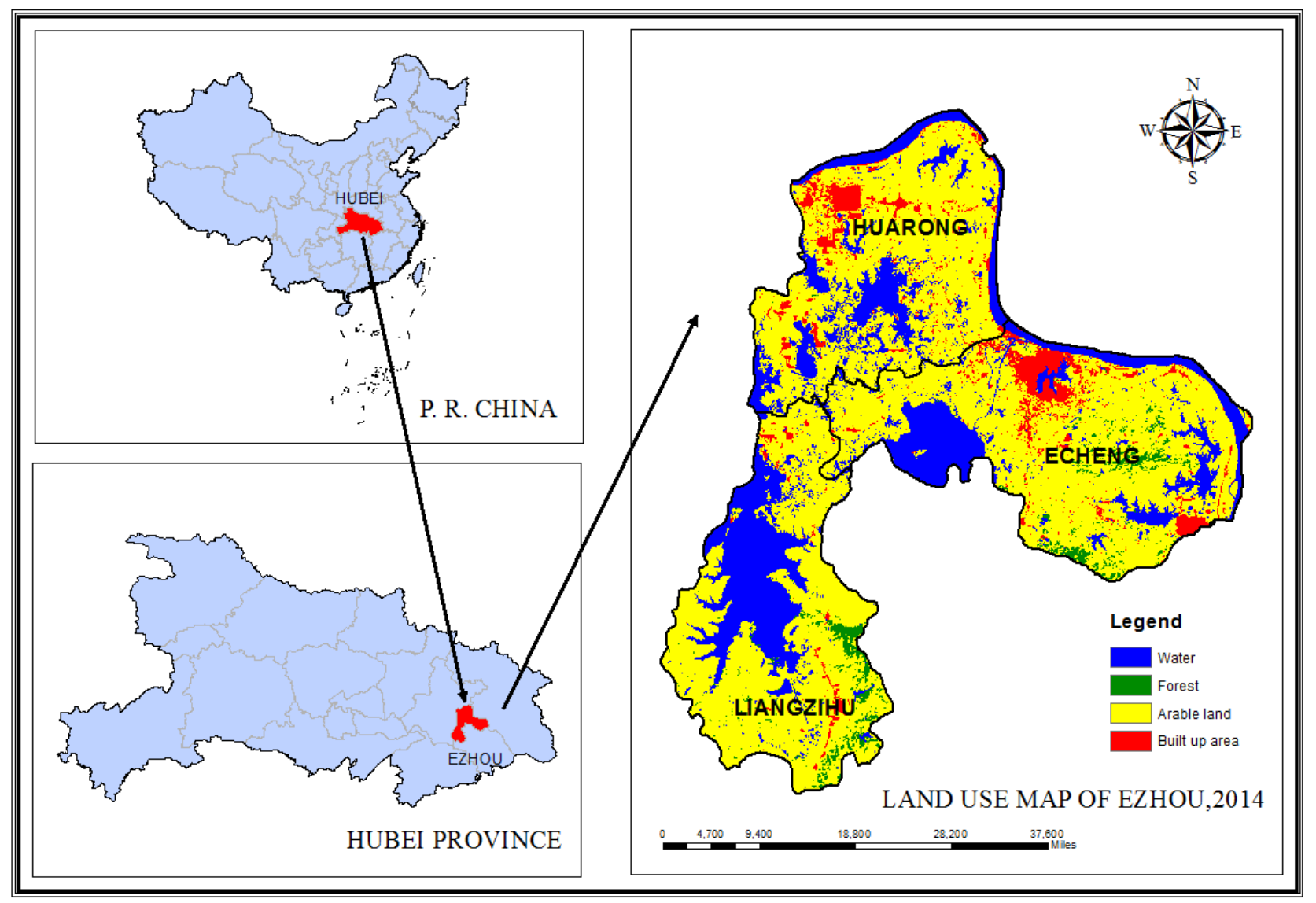

Fig. 1. The study area and its land use in 2014 
Both geographical and socio-economic data were used in this study. The geographic data includes the Land sat TM images taken in July 1998 and 2012, a Digital Elevation Model (DEM), the administrative boundary map and transportation map of Ezhou City. The remote sensing images and DEM data were collected from U.S. Geological Survey (USGS) with a spatial resolution of 30 meters. The remote sensing images were used to identify key landscape features related to urban development, including waterbodies, built-up areas, arable lands and forests. Physical attributes of the landscape including land slope and elevation, which were derived from the DEM data. In addition, the administrative boundary map was derived from the Global Administration Areas website (GAA|BWL, 2016) and the transportation net work data was digitalized based on Google Maps and Open Street Map. These data were used to analyse the transport network density in different district areas as a key impact factor for urban development. Socio-economic data such as population, gross industry output, gross domestic product, local government revenue, gross agricultural output and average income in 1998 and 2012 were derived from the 1999 and 2013 Ezhou Statistics Yearbooks.

\section{Methodology}

\section{Construction of the Suitability Indicator System}

An evaluation indicator system needs to be identified with respect to the envisaged purpose under consideration (Feizizadeh and Blaschke, 2013). The set of indicators should adequately represent the topic under consideration and contribute to the final goal (Prakash, 2003). According to Chen et al. (2010), land suitability evaluation is a process of multiple criteria assessment where the attributes of different criteria are to be obtained from spatial and non-spatial, qualitative and quantitative information under various conditions.

\section{Principles of Constructing the Indicator System}

The selection of urban development suitability indicators for urban development was based on the following principles.

\section{Comprehensiveness}

Urban development suitability is affected by not only geographical factors, but also socio-economic factors. Therefore, the indicator system for urban development suitability should reflect the multi-dimensional construct of environment conditions, economic conditions and human living conditions.

\section{Dynamics}

The indicator system should reflect the changing nature of the urban development suitability over time.
Therefore, both a spatial and temporal dimension of the indicator system should be reflected to better understand the conditions of future urban development.

\section{Independence}

Each indicator selected should represent a different aspect of the environmental, socio-economic and human dimensions to avoid the crossover of indicators.

\section{Data Accessibility}

The availability of data also constrains the selection of the indicators to a large extent. Reliable source of data should be available and accessible to quantify each of the indicators selected for assessment.

\section{Composition of the Indicator System}

A suite of environmental, economic and social indicators were selected based on the selection principles to formulate the urban development suitability indicator system. The environment condition indicators include percentage of waterbodies in total land area, land slope and elevation. The economic condition indicators describe various aspects of its economic status for future urban development, including population density, gross industry output, GDP, local government revenue and gross agricultural output. The human living condition indicators measure its conditions for human settlement as well as its attractiveness for migration. This includes the proportion of urban built-up areas to its total area, the per capita annual net income of rural households and the transportation network density. The transportation network density is defined as the total length of transportation networks per square kilometre. Table 1 lists the three sets of indicators selected for urban development suitability assessment in Ezhou City.

\section{Data Processing}

According to the indicator system built in the Part 3.1.2, the raw data are processed in the following approaches.

For the geographical data, the percentage of waterbodies and existing built up areas are derived from the Ezhou land-use maps in 1998 and 2012. In order to get the land-use maps, the unsupervised classification method has been used in the software ENVI 5.1. According to the LUCC classification system of biology environment remote sensing investigation in the Middle East China, the Lands at TM images in 1998 and 2012 are classified into 60 clusters by the Iterative SelfOrganizing Data Analysis Technique (ISODATA), as 60 clusters can cover almost all dominant classes in Ezhou (Wu et al., 2010). After all the classes were identified one by one, with the help of high resolution images from Google map and Near map, they were then grouped into four final land-use types, which are built up area, waterbody, arable land and forest. 


\begin{tabular}{|c|c|c|c|c|}
\hline Dimensions & Indicators (abbreviation) & Unit & Indicator no. & Description \\
\hline \multirow[t]{3}{*}{$\begin{array}{l}\text { Environmental } \\
\text { condition }\end{array}$} & Waterbody (W) & $\%$ & 1 & $\begin{array}{l}\text { The percentage of waterbodies in the area. } \\
\text { Waterbodies are considered valuable for ecosystem } \\
\text { conservation but a constraint to urban development. }\end{array}$ \\
\hline & Slope (S) & Degree & 2 & $\begin{array}{l}\text { The average land slop of each land unit under assessment. } \\
\text { Steep land slope is disadvantageous for urban construction } \\
\text { which incurs higher cost (Kumar and Shaikh, 2012). }\end{array}$ \\
\hline & Elevation (E) & $\mathrm{m}$ & 3 & $\begin{array}{l}\text { The average elevation of each land unit under assessment. } \\
\text { In general, areas with lower elevation are more attractive } \\
\text { for development as higher elevation could increase the } \\
\text { construction cost. }\end{array}$ \\
\hline \multirow[t]{5}{*}{$\begin{array}{l}\text { Economic } \\
\text { condition }\end{array}$} & Population Density (PD) & Pop./ ha ${ }^{2}$ & 4 & $\begin{array}{l}\text { These indicators represent the economic environment in } \\
\text { the study area. Good economic condition scan promote } \\
\text { urban development in this area. }\end{array}$ \\
\hline & Gross industry output (GIO) & $10^{4} \mathrm{RMB}$ & 5 & The percentage of the built up area. The area with high \\
\hline & Gross domestic product (GDP) & $10^{8} \mathrm{RMB}$ & 6 & percentage of built-up area reflects it is in highly \\
\hline & Local government revenue (LGR) & $10^{4} \mathrm{RMB}$ & 7 & developed status and will be more likely to expand in the \\
\hline & Gross agricultural output (GAO) & $10^{4} \mathrm{RMB}$ & 8 & future. \\
\hline \multirow[t]{5}{*}{ Living condition } & Existing built-up area (EBA) & $\%$ & 9 & \\
\hline & $\begin{array}{l}\text { Per capita annual net income of } \\
\text { rural household (PCANIRH) }\end{array}$ & RMB $¥$ & 10 & $\begin{array}{l}\text { This accounts for the total annual income of rural } \\
\text { households after deducting the expenses for productive } \\
\text { and non-productive business operations, payment for taxes } \\
\text { and payment for collective units for their contracted tasks } \\
\text { and the subsidy. Areas with its residents having higher net } \\
\text { income will attract in-migration and therefore promote } \\
\text { urban development. }\end{array}$ \\
\hline & Density of Transport Network (DTN) & $\mathrm{m} / \mathrm{ha}^{2}$ & 11 & $\begin{array}{l}\text { This is defined as the total length of transportation } \\
\text { network per square kilometre. Higher transportation } \\
\text { density will increase the accessibility to other places which } \\
\text { is advantageous for resident's living condition } \\
\text { improvement and urban development. }\end{array}$ \\
\hline & Proximity to Main Road (PMR) & $\mathrm{m}$ & 12 & $\begin{array}{l}\text { The average distance from each land unit under } \\
\text { assessment to main road in study area. An area closer to } \\
\text { main road would be more attractive for urban } \\
\text { development. }\end{array}$ \\
\hline & Proximity to Built-up Area (PBA) & $\mathrm{m}$ & 13 & $\begin{array}{l}\text { The average distance from each land unit under } \\
\text { assessment to any existing urban built-up area. Area closer } \\
\text { to existing urban areas will be more favourable for urban } \\
\text { development (Yeh and } \mathrm{Li}, 1998) \text {. }\end{array}$ \\
\hline
\end{tabular}

Post-classification work was carried out by means of the Majority/minority analysis tool with the core $3 \times 3$ in ENVI 5.1. The slope and elevation were extracted from the Digital Elevation Model (DEM) data in Ezhou using Arc GIS 10.2.2. The transport network density was calculated according to the Ezhou transportation map and administration map. The proximity to main roads and built up area was obtained by the buffer analysis for roads and built up areas in 1998 and 2012. As for nongeographical data such as the economic indicators, the data was obtained directly from Ezhou Statistics Yearbook in 1999 and 2013.

In addition, the waterbodies, slope, elevation and proximity to main road and built up area could negatively impact urban development, which means that higher values of these indicators will constrain the development in study area. In order to turn all the aforementioned indicators into positive factors for urban development, the reciprocal of the original values in the environment condition were used for the data standardization and final calculation of urban development suitability.

\section{Data Standardization}

Given the multiple dimensions of the indicators, data standardization is required to remove the impact of different measurement unit of the indicators to the overall assessment result. The commonly used method for data standardization is the Z-score approach which results in a [0-1] scaling. The general formula is given as follows:

$$
x^{\prime}=\frac{x-\min (x)}{\max (x)-\min (x)}
$$

where, $x$ is an original value; $x^{\prime}$ is the standardized value of $x ; \max (x)$ and $\min (x)$ denote respectively the maximum and minimum value in the dataset.

This standardization approach is suitable for a time series data where the mean value and standard deviation are meaningful measures of the entire time series data. In a situation where a comparison of multiple variables over two time points is required, as is the case when we assess and compare the land suitability in Ezhou in the years 1998 and 2012, Equation 1 would not be useful for 
data standardisation. Instead, a new approach was proposed to standardize the input data across the multiple geographical units of the city region rather than over time, which also removes the impact of the measurement units for each indicator across the region. Given that, the data in this research will be standardized according to the following formula:

$$
X_{i}=\frac{x_{i}}{\sum_{i}^{n} x_{i}}
$$

where, $x_{i}$ represents the original value of the indicator $i$; $X_{i}$ denotes the standardized value of $x_{i} ; n$ is the number of cases (or geographical units being assessed); $\sum_{i}^{n} x_{i}$ is the sum of all cases for indicators $i$.

Through this standardization using Formula 2, the original values of all indicators will be transformed into a value ranging from 0 to 1 , which will be used to calculate the suitability value using the EAP method.

\section{The Entire-Array-Polygon Model}

Using the standardized data representing the thirteen indicators, a radar chart is produced with 13 axes evenly spread out over a 360 degree horizon for each geographical unit under assessment. Each of the 13 axes corresponds to one indicator and the length of the axe is determined by the value of the indicator being mapped along the axe direction, resulting in one irregular polygon the Entire-Array-Polygon for each land unit. This EAP is mapped over the full spectrum of a regular polygon with thirteen axes at a length of 1 for each axe (Fig. 2). Hence, the synthesised suitability index can be calculated as a ratio of the irregular polygon over the entire regular polygon area, as shown below:

$$
\begin{aligned}
& I=\frac{S_{\text {irregular } P}}{S_{\text {regular } P}} \\
& =\frac{\frac{1}{2} X_{1} \cdot X_{2} \sin \theta+\frac{1}{2} X_{2} \cdot X_{3} \sin \theta+\cdots \frac{1}{2} X_{n} \cdot X_{1} \sin \theta}{\frac{1}{2} U \cdot U \cdot \sin \theta \cdot n} \\
& =\frac{\sum_{i \neq j}^{i, j} X_{i} \cdot X_{j}}{n}
\end{aligned}
$$

where, $I$ is the synthesised suitability index; $S_{\text {irregular } P \text {, }}$ $S_{\text {regular } P}$ represent the area of the irregular and regular polygon; $\theta$ is the angle of two adjacent axes in the radar chart; $X_{i}, X_{j}$ denote the different standardized values of its indicators; $i, j$ denotes the indicator number; $n$ represents the total number of indicators and $U$ indicates the upper limit of the standardized value which is 1 in this research.

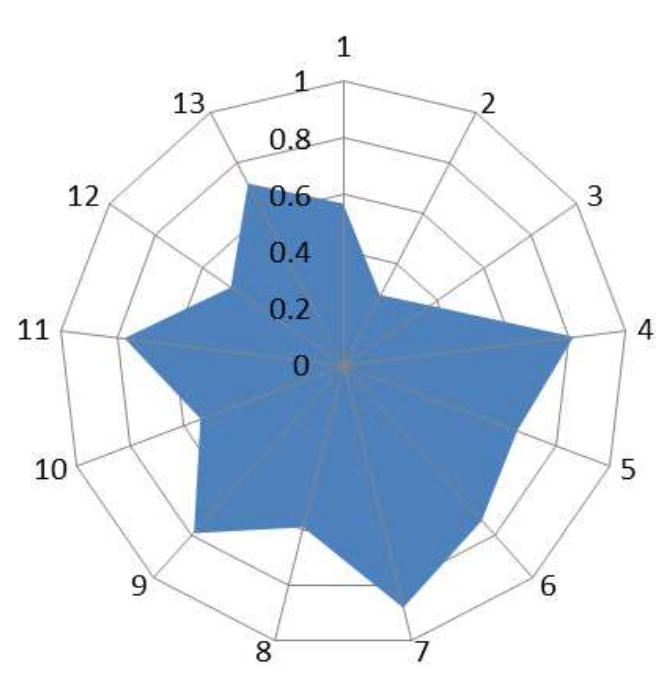

Fig. 2. A radar chart illustrating the Entire-Array-Polygon model for one geographical unit under assessment

\section{Results and Discussion}

\section{Data Processing Results}

Referring to the formulated indicator system, data process and standardization method in aforementioned part, Table 2 presents the raw data collected in accordance with the indicators selected to assess its urban development suitability and the standardised data using Equation 2.

\section{EAP Maps}

Using the EAP method, the land development suitability for each of the district in Ezhou in 1998 and 2012 was calculated and presented in Table 3 and mapped in Fig. 3.

Comparing the urban development suitability polygons in 1998 and 2012, the environmental conditions changed very slightly, except for the waterbody percentage in Liangzihu having increased $6.36 \%$, which is due to the effort made to protect the lake and fishing industry during this period. Economic conditions, on the other hand, increased dramatically in all the districts; the Gross Domestic Product of all the districts in 2012 is almost triple of that in 1998. The great achievement in economic conditions could have not only provided the economic support for urban construction, but also attract more industries and companies' investment, which is regarded as the positive incentives for urban development. At the same time, living conditions have also been greatly improved; the average income of all the districts in 2012 is more than twice that in 1998.

Based on the urban development suitability polygon in 1998 and 2012, the urban development suitability could be calculated according the formula (2) and the results has been shown in Fig. 4. 


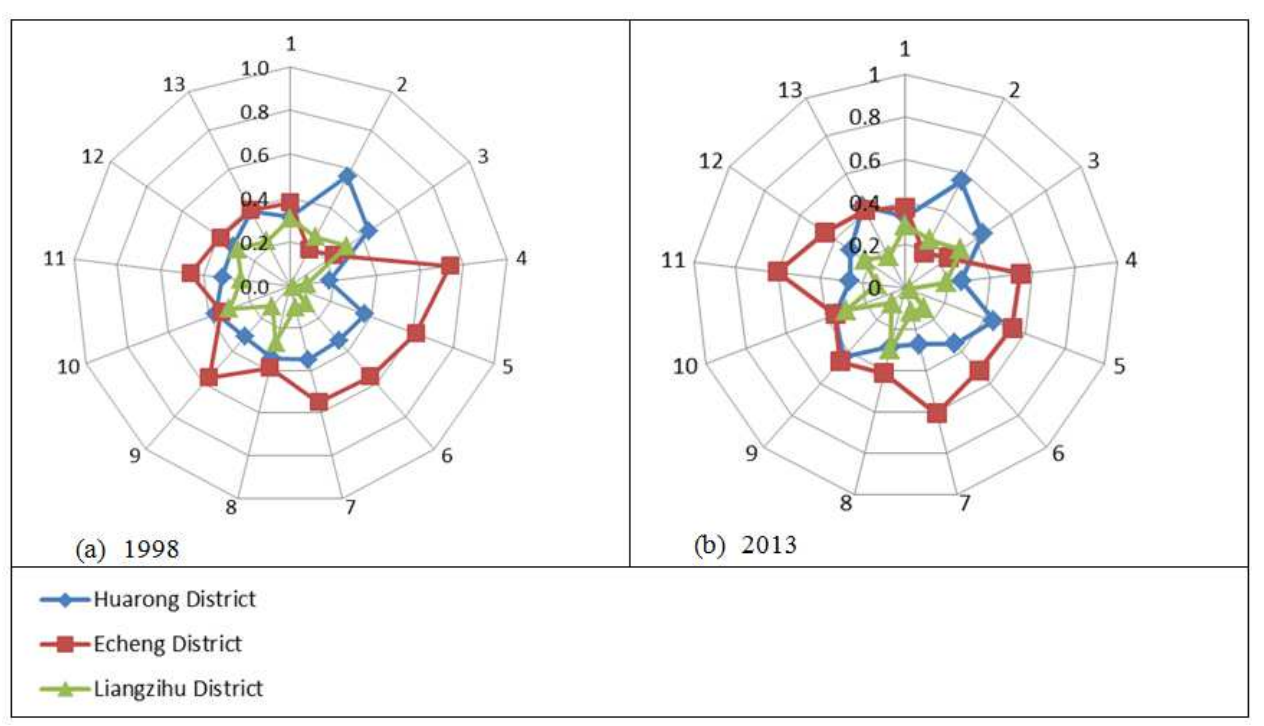

Fig. 3. Urban development suitability polygons for the three districts in Ezhou City in 1998 (a) and 2012 (b). The number 1 to 13 shown on the radar polygon corresponds to each of the indicators listed in Table 2

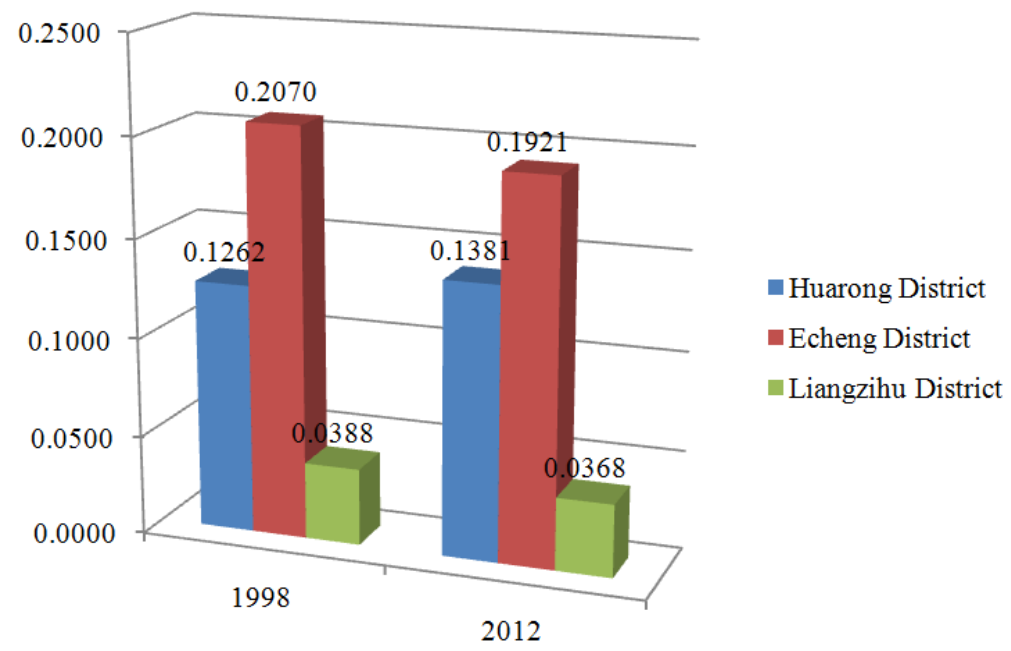

Fig. 4. Urban development suitability in Ezhou, 1998 and 2012

Table 2. Data for urban development suitability indicators in Ezhou, 1998 and 2012

\begin{tabular}{|c|c|c|c|c|c|c|c|c|c|c|c|c|c|c|}
\hline \multirow[b]{3}{*}{ Dimensions } & \multirow[b]{3}{*}{ Indicators } & \multirow[b]{3}{*}{$\begin{array}{l}\text { Indicator } \\
\text { No. }\end{array}$} & \multicolumn{6}{|l|}{ Raw data } & \multicolumn{6}{|c|}{ Standardised data } \\
\hline & & & \multicolumn{3}{|l|}{1998} & \multicolumn{3}{|l|}{2012} & \multicolumn{3}{|l|}{1998} & \multicolumn{3}{|l|}{2012} \\
\hline & & & $\begin{array}{l}\text { Huarong } \\
\text { district }\end{array}$ & $\begin{array}{l}\text { Echeng } \\
\text { district }\end{array}$ & $\begin{array}{l}\text { Liangzihu } \\
\text { district }\end{array}$ & $\begin{array}{l}\text { Huarong } \\
\text { district }\end{array}$ & $\begin{array}{l}\text { Echeng } \\
\text { district }\end{array}$ & $\begin{array}{l}\text { Liangzihu } \\
\text { district }\end{array}$ & $\begin{array}{l}\text { Huarong } \\
\text { district }\end{array}$ & $\begin{array}{l}\text { Echeng } \\
\text { district }\end{array}$ & $\begin{array}{l}\text { Liangzihu } \\
\text { district }\end{array}$ & $\begin{array}{l}\text { Huarong } \\
\text { district }\end{array}$ & $\begin{array}{l}\text { Echeng } \\
\text { district }\end{array}$ & $\begin{array}{l}\text { Liangzihu } \\
\text { district }\end{array}$ \\
\hline \multirow{3}{*}{$\begin{array}{l}\text { Environmental } \\
\text { condition }\end{array}$} & $\mathrm{W}$ & 1 & 24.8 & 20.4 & 25.1 & 24.5 & 22.7 & 31.5 & 0.3120 & 0.3793 & 0.3087 & 0.3494 & 0.3781 & 0.2724 \\
\hline & S & 2 & 0.3 & 0.8 & 0.6 & 0.3 & 0.8 & 0.6 & 0.3536 & 0.3383 & 0.3081 & 0.3536 & 0.3383 & 0.3081 \\
\hline & $\mathrm{E}$ & 3 & 22.1 & 39.6 & 30.8 & 22.1 & 39.6 & 30.8 & 0.3903 & 0.2829 & 0.3267 & 0.3903 & 0.2829 & 0.3267 \\
\hline \multirow{5}{*}{$\begin{array}{l}\text { Economic } \\
\text { condition }\end{array}$} & PD & 4 & 156 & 636 & 69 & 516 & 1060 & 373 & 0.1808 & 0.7386 & 0.0806 & 0.2649 & 0.5437 & 0.1913 \\
\hline & GID & 5 & 145952 & 244943 & 6558 & 459447 & 362770 & 9319 & 0.3672 & 0.6163 & 0.0165 & 0.5525 & 0.4363 & 0.0112 \\
\hline & GDP & 6 & 20.9 & 34.6 & 6.8 & 74.5 & 93 & 22.7 & 0.3361 & 0.555 & 0.1089 & 0.3916 & 0.489 & 0.1194 \\
\hline & LGR & 7 & 7492.5 & 11762.2 & 2159 & 47666 & 82684 & 10539 & 0.3499 & 0.5493 & 0.1008 & 0.3383 & 0.5869 & 0.0748 \\
\hline & GAO & 8 & 48580 & 54968 & 38140 & 305098 & 305098 & 262809 & 0.3429 & 0.388 & 0.2692 & 0.3495 & 0.3495 & 0.3010 \\
\hline & EBA & 9 & 2.5 & 4.4 & 1 & 6.4 & 10 & 2.6 & 0.3130 & 0.5614 & 0.1256 & 0.3361 & 0.5277 & 0.1362 \\
\hline \multirow[t]{4}{*}{ condition } & PCANIRH & 10 & 2720 & 2510 & 2220 & 5792 & 5887 & 4779 & 0.3651 & 0.3369 & 0.2980 & 0.3519 & 0.3577 & 0.2904 \\
\hline & DTN & 11 & 223.7 & 330.5 & 163.1 & 314.1 & 726.1 & 163.7 & 0.3119 & 0.4607 & 0.2274 & 0.2609 & 0.6032 & 0.1359 \\
\hline & PMR & 12 & 1967 & 1618.7 & 2143.7 & 1600.9 & 1089.8 & 2143.7 & 0.3192 & 0.3879 & 0.2929 & 0.3110 & 0.4568 & 0.2322 \\
\hline & PBA & 13 & 216 & 213 & 362.6 & 138 & 145.5 & 360.5 & 0.3832 & 0.3885 & 0.2282 & 0.4290 & 0.4068 & 0.1642 \\
\hline
\end{tabular}


Table 3. Urban development suitability index in Ezhou, 1998 and 2012

\begin{tabular}{|c|c|c|c|c|c|c|}
\hline \multirow[b]{2}{*}{ Places } & \multicolumn{3}{|l|}{1998} & \multicolumn{3}{|l|}{2012} \\
\hline & $\begin{array}{l}\text { Huarong } \\
\text { district }\end{array}$ & $\begin{array}{l}\text { Echeng } \\
\text { district }\end{array}$ & $\begin{array}{l}\text { Liangzihu } \\
\text { district }\end{array}$ & $\begin{array}{l}\text { Huarong } \\
\text { district }\end{array}$ & $\begin{array}{l}\text { Echeng } \\
\text { district }\end{array}$ & $\begin{array}{l}\text { Liangzihu } \\
\text { district }\end{array}$ \\
\hline Suitability index & 0.1236 & 0.2039 & 0.0436 & 0.1330 & 0.1975 & 0.0374 \\
\hline
\end{tabular}

Figure 4 shows that the urban development suitability of Echeng is the highest among the three districts in both 1998 and 2012. That is because Echeng is the political, economic and cultural centre of Ezhou, therefore bringing Echeng more political priorities and preferential policies for urban development than the other two districts. Due to these factors, Echeng has the best investment environment which attracts many industries and companies to invest and develop. In 2006, Ezhou Economic Development Zone was established in Echeng which accelerated the industry agglomeration and promoted urban economic development. Meanwhile, it created a significant numbers of job opportunities for surplus labour in rural areas every year, which greatly promote the urban and rural integration and urbanization. According to the Hubei statistics in 2013, Echeng's economy ranked 13th among all the county-level regions of Hubei Province and its urbanization rate reached $62.8 \%$ (HSB, 2014). However, for a long time, the economic development in Echeng has been dominated by resource-based industries. Due to the limited development space and natural resources, the urban development suitability decreased in 2012 .

Meanwhile, urban development is in progress in Huarong district. Huarong district is located in the north of Ezhou and adjacent with the Wuhan East Lake Hightech Development Zone the Wuhan Optical Valley. Great location advantage has brought Huarong a good opportunity for development. In 1990, Gedian Economic and Technological Development Zone was established in Huarong district which was the first economic and technological development zone approved by the Hubei government. However, due to the lack of policies to create a sound environment for attracting investment, the economy in Huarong increased smoothly until it was set up as the National Biological and New Medicine Industrial Base, or more colloquially, the "China Medicine Valley" in late 2001, which brought more industries and investment in Huarong. Meanwhile, it also reinforced the commercial interaction with Wuhan Optical Valley from then on.

As for the Liangzihu district, it is famous for Liangzi Lake which breeds the local fishery and tourism. As mountains and waterbodies dominate its landscape, the space for development is limited and it has the lowest population density in Ezhou, which hindered its economic development. In 2010, Liangzihu Ecological Protection Planning was approved by the Hubei provincial government in order to remedy its ecosystem and restrict its development. Given this, it has the lowest urban development suitability compared to other districts in the two time points. The suitability in Liangzihu also decreased slightly during this period.

As such, the computed urban development suitability by EAP method could effectively illustrate the development status in three different districts in Ezhou city and assist investigating the potential development problems. By considering balancing the economic growth and environment protection in urbanisation process, this research evaluate the urban development suitability from the aspects of economic condition, environmental condition and human living condition. The results could support the urban planner and government officials to make policies so as to achieve a sustainable urban development in the future. However, due to the limitation of socio economic data, only few representative indicators are selected in each aspects and the geographic unit for assessment is confined in the district level which could only provide a macro direction for its regional development in Ezhou. With the release of more fine-scaled socio economic data, the indicator system will be enriched and the suitability assessed will be more precise by EAP method in the future.

\section{Conclusion}

Urban development suitability evaluation could help planners reconsider the current urban development trajectory and make urban blueprint from the perspective of urban sustainable development and urban rural integration. This research prefers to evaluate the urban development suitability from a macro perspective the district level- with the consideration of regional geographical and social-economic condition. It could assist the planner and government to identify the specific suitable zones for future development and readjust development policies accordingly. In this study, the Entire-Array-Polygon model has been introduced to evaluate the urban development suitability of Echeng, Huarong and Liangzihu districts in Ezhou, Hubei province, P. R. China in 1998 and 2012. The conclusions are as follows.

First of all, compared to methods which require assigning weights to indicators by experts, the EntireArray-Polygon model effectively avoids the inaccuracies resulting from subjectiveness. The polygons are easily used for problems-diagnosing and policy-making because the advantages and disadvantages for urban 
development in different districts can be visually analysed using the polygon chart. In addition, the synthesis index in this model which denotes the urban development suitability integrates all the indicators without preferences and priorities, thereby making the final result more rational and objective.

Secondly, the indicator system for the evaluation of urban development suitability is built from the perspective of environment, economic and resident living conditions. These aspects not only comprehensively reflect the requirements for urban development, but also indicate weak areas that require further development, for example the protection of ecosystems and the improvement of resident living condition. However, due to the limited accessibility of data sources, there are only a few geographical and social-economic indicators available for the suitability evaluation in this research.

Thirdly, the urban development suitability of the Echeng, Huarong and Liangzihu districts shows that during the 15 years' development, Echeng still has the highest development suitability due to its dominant and leading position in Ezhou for a long time. However, the decrease of suitability in Echeng shows that a bottleneck for the urban development has appeared. It needs industrial upgrading and a transition from resource-based and labour-intensive industries so as to protect the environment and promote economic development. This will reduce the environment degradation caused by economic growth which is an urgent issue in contemporary China's urbanisation process. In Huarong's case, due to the economic improvement especially for the rapid development of Gedian Economic and Technological Development Zone and National Biological and New Medicine Industrial Base, Huarong experienced the urban development suitability increase during this period. Meanwhile, the suitability in Liangzihu decreased slightly, which is attributed to its limited space for development and the protection of the Liangzi lake ecosystem.

Lastly, according to the regional urban development suitability, the local government could readjust its development policies so as to better improve regional development. For example, Echeng could shift its industry types from natural resource-based industries to high-tech and service industries. Huarong could take good advantage of location and strengthen its economic connections with Wuhan Optical Valley so as to improve its competence and accelerate its urban development. Maintaining the rich natural resources and beautiful scenery, Liangzihu could continuously develop its local tourism and fishery in order to make it as the liveable and prosperous place in Ezhou.

The application of EAP method in Ezhou shows that it is an effective approach in assessing urban development suitability with comprehensively considering local economic growth, environment protection and resident's living welfare. In this case study, due to the limitation of data accessibility, the indicator system contains few representative indicators in each aspect and the geographic unit is confined to district level. However, with more date release in the future or in other area, the EAP method would have better applicability in assessing urban development suitability.

\section{Acknowledgement}

This work is financially supported by the China Scholarship Council and University of Queensland International Scholarship. We thank the three anonymous referees for their constructive suggestions and valuable comments.

\section{Author's Contributions}

Long Cheng: Data collection, ressearch design and paper writing.

Yan Liu: Refine research franework and polish english writing.

\section{Ethics}

This article is original and contains unpublished material. The corresponding author confirms that all of the other authors have read and approved the manuscript and no ethical issues involved.

\section{References}

Akinci, H., A.Y. Ozalp and B. Turgut, 2013. Agricultural land use suitability analysis using GIS and AHP technique. Comput. Electron. Agric., 97: 71-82. DOI 10.1016/j.compag.2013.07.006

Chandio, I.A., A.N. Matori, D.U. Lawal and S. Sabri, 2011. GIS-based land suitability analysis using AHP for public parks planning in Larkana city. Modern Applied Sci., 5: 177-189.

DOI: $10.5539 /$ mas.v5n4p 177

Chen, Y., S. Khan and Z. Paydar, 2010. To retire or expand? A fuzzy GIS-based spatial multi-criteria evaluation framework for irrigated agriculture. Irrigat. Drainage, 59: 174-188.

DOI: $10.1002 /$ Ird.470

Cheng, L. and J. Dong, 2013. Land intensive use evaluation for Wuhan metropolitan agglomeration based on Entire-array-polygon evaluation model. Proceedings of the 2nd International Conference on Agro-Geoinformatics, Aug. 12-16, IEEE Xplore Press, Fairfax, VA., pp: 87-92.

DOI: 10.1109/Argo-Geoinformatics.2013.6621885 
Collins, M.G., F.R. Steiner and M.J. Rushman, 2001. Land-use suitability analysis in the United States: historical development and promising technological achievements. Environ. Manage., 28: 611-621. DOI: $10.1007 / \mathrm{s} 002670010247$

Deng, X.Z., J.K. Huang, S. Rozelle and E. Uchida, 2008. Growth, population and industrialization and urban land expansion of China. J. Urban Econom., 63: 96-115. DOI: 10.1016/j.jue.2006.12.006

Dong, J., D. Zhuang, X. Xu and L. Ying, 2008. Integrated evaluation of urban development suitability based on remote sensing and GIS techniques-a case study in Jingjinji Area, China. Sensors, 8: 5975-5986. DOI: 10.3390/s8095975

Feizizadeh, B. and T. Blaschke, 2012. Land suitability analysis for Tabriz County, Iran: A multi-criteria evaluation approach using GIS. J. Environ. Plann. Manage., 56: 1-23.

DOI: $10.1080 / 09640568.2011 .646964$

Feizizadeh, B. and T. Blaschke, 2013. Land suitability analysis for Tabriz County, Iran: A multi-criteria evaluation approach using GIS. J. Environ. Plann. Manage., 56: 1-23.

DOI: $10.1080 / 09640568.2011 .646964$

Girvetz, E.H., J.H. Thorne, A.M. Berry and J.A.G. Jaeger, 2008. Integration of landscape fragmentation analysis into regional planning: A statewide multiscale case study from California, USA. Landscape Urban Plann., 86: 205-218.

DOI: 10.1016/j.landurbplan.2008.02.007

Glaeser, E., 2011. Triumph of the City: How our Greatest Invention Makes us Richer, Smarter, Greener, Healthier and Happier. 1st Edn., Penguin Publishing Group, New York, ISBN-10: 1101475676, pp: 352.

GAA|BWL, 2016. Global administrative areas $\mid$ Boundaries without limits.

Hopkins, L.D., 1977. Methods for generating land suitability maps: A comparative evaluation. J. Am. Inst. Planners, 43: 386-400.

DOI: $10.1080 / 01944367708977903$

HSB, 2014. 2013 Ezhou economic and social development statistics report. Hubei Statistic Bureau.

Jago-on, K.A., S. Kaneko, R. Fujikura, A. Fujiwara and T. Imai et al., 2009. Urbanization and subsurface environmental issues: An attempt at DPSIR model application in Asian cities. Sci. Total Environ., 407: 3089-3104. DOI: 10.1016/j.scitotenv.2008.08.004

Jain, K. and Y.V. Subbaiah, 2007. Site suitability analysis for urban development using GIS. J. Applied Sci., 7: 2576-2583. DOI: $10.3923 /$ jas.2007.2576.2583

Kienast, F., B. Degenhardt, B. Weilenmann, Y. Wager and M. Buchecker, 2012. GIS-assisted mapping of landscape suitability for nearby recreation. Landscape Urban Plann., 105: 385-399.

DOI: 10.1016/j.landurbplan.2012.01.015
Kumar, M. and V.R. Shaikh, 2012. Site suitability analysis for urban development using GIS based multicriteria evaluation technique. J. Ind. Society Rem. Sens., 41: 417-424. DOI: $10.1007 / \mathrm{s} 12524-012-0221-8$

Liu, R., K. Zhang, Z. Zhang and A.G. Borthwick, 2014. Land-use suitability analysis for urban development in Beijing. J. Environ. Manage., 145: 170-179. DOI: 10.1016/j.jenvman.2014.06.020

Liu, S.L., R. Sheng, Y.W. Zhang, X.J. Liu and X.J. Wang et al., 2013. Evolution assessment of China's three mega-city regions based on entirearray-polygon method. J. Shanghai Jiaotong Univ., 18: 756-762. DOI: 10.1007/s12204-013-1462-6

Lu, D., 2011. Introduction: China's Great Urbanization. In: The Great Urbanization of China, Lu, D. (Ed.), World Scientific, Singapore, ISBN-10: 9814287806 , pp: $1-10$.

Malczewski, J., 2006. GIS-based multicriteria decision analysis: A survey of the literature. Int. J. Geographical Inform. Sci., 20: 703-726. DOI: $10.1080 / 13658810600661508$

Marull, J., J. Pino, J.M. Mallarach and M.J. Cordobilla, 2007. A land suitability index for strategic environmental assessment in metropolitan areas. Landscape Urban Plann., 81: 200-212. DOI: 10.1016/j.landurbplan.2006.11.005

Mendas, A. and A. Delali, 2012. Integration of MultiCriteria Decision Analysis in GIS to develop land suitability for agriculture: Application to durum wheat cultivation in the region of Mleta in Algeria. Comput. Electr. Agric., 83: 117-126. DOI: 10.1016/j.compag.2012.02.003

NBSC, 1978. China statistical yearbook. National Bureau of Statistics of China.

NBSC, 2014. China statistical yearbook. National Bureau of Statistics of China.

Nolè, G., B. Murgante, G. Calamita, A. Lanorte and R. Lasaponara, 2014. Evaluation of urban sprawl from space using open source technologies. Ecol. Inform., 26: 151-161. DOI: 10.1016/j.ecoinf.2014.05.005

Pereira, J.M.C. and L. Duckstein, 1993. A multiple criteria decision-making approach to GIS-based land suitability evaluation. Int. J. Geographical Inform. Syst., 7: 407-424.

DOI: $10.1080 / 02693799308901971$

Prakash, T.N., 2003. Land suitability analysis for agricultural crops: A fuzzy multicriteria decision making approach. MSC Theses, International Institute for Geo-Information Science and Earth Observation Enschede, The Netherland.

Saaty, T.L., 1980. The Analytic Hierarchy Process: Planning, Priority Setting, Resource Allocation. 2nd Edn., McGraw-Hill, New York, ISBN-10: 0070543712, pp: 287. 
Steiner, F., L. McSherry and J. Cohen, 2000. Land suitability analysis for the upper Gila River watershed. Landscape Urban Plann., 50: 199-214. DOI: 10.1016/S0169-2046(00)00093-1

Store, R. and J. Kangas, 2001. Integrating spatial multicriteria evaluation and expert knowledge for GISbased habitat suitability modelling. Landscape Urban Plann., 55: 79-93.

DOI: $10.1016 / \mathrm{S} 0169-2046(01) 00120-7$

UNPF, 2007. State of world population 2007 unleashing the potential of urban growth. United Nations Population Fund.

Wang, S. and X. Bian, 2007. Synthesis evaluation with entire-array-polygon method to ecological economic system of Funing County in Jiangsu Province. Environ. Monit. Assess, 127: 537-545. DOI: $10.1007 / \mathrm{s} 10661-006-9300-\mathrm{Z}$

Wu, H., X. Chen, Z. Li, S. Wang and W. Cui et al., 2010. Identifying Spatial Patterns of Land Use and Cover Change at Different Scales Based on SelfOrganizing Map. In: Advances in Neural Network Research and Applications, Zeng, Z. and J. Wang (Eds.), Springer Berlin Heidelberg, pp: 355-361.
Wu, Q., R.S. Wang, H.Q. Li and X.B. Xu, 2005. The indices and the evaluation method of eco-city. Acta Ecol. Sinica, 25: 2090-2095.

$\mathrm{Xu}$, E.Q. and H.Q. Zhang, 2013. Spatially-explicit sensitivity analysis for land suitability evaluation. Applied Geography, 45: 1-9.

DOI: 10.1016/j.apgeog.2013.08.005

$\mathrm{Xu}, \mathrm{K}$. , C.F. Kong, J.F. Li, L.Q. Zhang and C.L. Wu, 2011. Suitability evaluation of urban construction land based on geo-environmental factors of Hangzhou, China. Comput. Geosci., 37: 992-1002. DOI: 10.1016/j.cageo.2011.03.006

Yeh, A.G.O. and X. Li, 1998. Sustainable land development model for rapid growth areas using GIS. Int. J. Geographical Inform. Sci., 12: 169-189. DOI: $10.1080 / 136588198241941$

Youssef, A.M., B. Pradhan and E. Tarabees, 2010. Integrated evaluation of urban development suitability based on remote sensing and GIS techniques: Contribution from the analytic hierarchy process. Arabian J. Geosci., 4: 463-473.

DOI: $10.1007 / \mathrm{s} 12517-009-0118-1$ 